\title{
Cancer survival in Qidong between 1972 and 2011: A population-based analysis
}

\author{
JIAN-GUO CHEN ${ }^{1,2}$, JIAN ZHU ${ }^{1}$, YONG-HUI ZHANG ${ }^{1}$, YI-XIN ZHANG ${ }^{2}$, \\ DENG-FU YAO ${ }^{3}$, YONG-SHENG CHEN ${ }^{1}$, JIAN-HUA LU ${ }^{1}$, LU-LU DING $^{1}$, HAI-ZHEN CHEN $^{2}$, \\ CHAO-YONG ZHU ${ }^{2}$, LI-PING YANG ${ }^{2}$, YUAN-RONG ZHU ${ }^{1}$ and FU-LIN QIANG ${ }^{2}$ \\ ${ }^{1}$ Qidong Cancer Registry, Qidong Liver Cancer Institute, Qidong, Jiangsu 226200; ${ }^{2}$ Nantong University Tumour Hospital/Institute, \\ Nantong, Jiangsu 226361; ${ }^{3}$ Affiliated Hospital of Nantong University, Nantong, Jiangsu 226000, P.R. China
}

Received May 17, 2016; Accepted March 7, 2017

DOI: $10.3892 / \operatorname{mco} .2017 .1234$

\begin{abstract}
Population-based cancer survival is an improved index for evaluating the overall efficiency of cancer health services in a given region. The current study analysed the observed survival and relative survival of leading cancer sites from a population-based cancer registry between 1972 and 2011 in Qidong, China. A total of 92,780 incident cases with cancer were registered and followed-up for survival status. The main sites of the cancer types, based on the rank order of incidence, were the liver, stomach, lung, colon and rectum, oesophagus, breast, pancreas, leukaemia, brain and central nervous system (B and CNS), bladder, blood [non-Hodgkin's lymphoma (NHL)] and cervix. For all malignancies combined, the 5-year observed survival was $13.18 \%$ and the relative survival was $15.80 \%$. Females had higher observed survival and relative survival (19.32 and 22.71\%, respectively) compared with males (9.63 and $11.68 \%$, respectively). The cancer sites with the highest five-year relative survival rates were the female breast, bladder, cervix and colon and rectum; followed by NHL, stomach, B and CNS cancer and leukaemia. The poorest survival rates were cancers of oesophagus, lung, pancreas and liver. Higher survival rates were observed in younger patients compared with older patients. Cancers of the oesophagus, female breast and bladder were associated with higher survival in middle-aged groups. Improved survival rates in the most recent two 5-year calendar periods were identified for stomach,
\end{abstract}

Correspondence to: Dr Jian-Guo Chen, Qidong Cancer Registry, Qidong Liver Cancer Institute, Qidong, Jiangsu 226200, P.R. China E-mail: chenjg@vip.sina.com

Abbreviations: B and CNS, brain and central nervous system; NHL, non-Hodgkin's lymphoma; IARC, International Agency for Research on Cancer; DCN, death certificate notifications; DCO, death certificate only; MV, morphological verification; ASRw, age-standardized rate by world population

Key words: neoplasm, observed survival, relative survival, population-based cancer registration, epidemiology lung, colon and rectum, oesophagus, female breast and bladder cancer, as well as leukaemia and NHL. The observations of the current study provide the opportunity for evaluation of the survival outcomes of frequent cancer sites that reflects the changes and improvement in a rural area in China.

\section{Introduction}

Cancer survival is an index for evaluating the effect of treatment of patients in specific settings, whether used to define outcomes in clinical trials or as an indicator of the overall efficiency of the cancer health services in a given region or country for the general public. There have been numerous reports on cancer survival revealing improvements through various therapies, derived from hospital-based datasets (1-4). However, there are few reports on the general efficiency of cancer health services derived from long-term population-based cancer registration systems (5-10).

Nation-wide population-based cancer registration, such as that found in Europe, makes survival analysis possible, and has revealed the impact of various socio-economic factors, natural histories, health-seeking behaviours, awareness, early detection practices and treatment availability and accessibility on cancer survivorship $(5,10,11)$. In less developed countries, however, there were relatively few datasets to provide population-based cancer survival analyses until the first volume of the International Agency for Research on Cancer's report on Cancer Survival in Developing Countries (6) was published in 1998. It includes survival data from 10 cancer registries in 5 countries. In 2011, IARC published its second scientific publication on Cancer Survival in Africa, Asia, the Caribbean and Central America (7), which includes survival data from 27 cancer registries in 14 countries.

These international cancer survival studies $(5-7,10)$ have provided important information concerning differences in populations observed between and within countries, and valuable insights for future planning and investment by governments in primary prevention activities, early detection initiatives and tertiary care to achieve meaningful cancer control (7). A global coordinative research report of survival from 279 population-based registries was published recently (12), and several nationwide research reports were issued to estimate 
the prognosis of cancer, but these included only a short time period $(13,14)$, or site-specific survival from population based data (15-17). For providing a long-term assessment of population-based cancer data, this paper provides a systematic analysis of cancer survival for the period of 1972-2011 in Qidong, China.

\section{Materials and methods}

The Qidong Cancer Registry. The Qidong Cancer Registry was designed as a population-based cancer registry in 1972 when the Qidong Liver Cancer Institute was established (18). Soon thereafter, this registry was designated by the local health authority as a compulsory reporting system implemented by health care workers in all health services. In 1974, the Qidong Cancer Registry started to establish an all cause-of-death certificate reporting system (Qidong All-Death-Cause Registration), as one of the seven national disease-monitoring rural locations for vital statistics under the supervision of the Health Ministry of PR China (19). This vital statistics system makes available the outcome of any patients with cancer patients who succumbed to the disease or are still alive. At present, this cancer registry has joined the national monitoring programme (the National Cancer Registration Network) of the National Central Cancer Registry of China supported by the Ministry of Health of China (20).

Case-finding. Mixed methods were employed for case finding and follow-up, as described elsewhere $(6,7)$. Briefly, district and township health services (or hospitals) were responsible for the registration and follow-up of incident cases and mortalities from cancer cases diagnosed in outpatient departments, or during hospitalization (including those returning home following hospitalization outside of Qidong). Upon discovering any 'new' patient(s) with cancer in the covered area, registration personnel would first check to confirm the case was new, and then considered it as incident case for inquiring about the patient's demographic features such as name, gender, age, address, marital status and occupation, as well as main items on the date and basis of diagnosis, treatment (if any) and hospital name(s). These data were recorded on registers, lists, or cards issued by Qidong Cancer Registry, and then reported monthly to Qidong Cancer Registry. When incident case(s) later died at home or in a hospital, the registration personnel would add the date of death to the existing record in the registry. Meanwhile a death certificate, issued by the physician in charge of the case or collected from the registrants, would be send to the current registry for entry and storage in the archives.

Follow-up methods. In practice, cancer lists and death certificate notifications (DCN) were reported monthly. Any cases of mortality from cancer were matched again with the DCN in our registry. For those alive, repeated scrutiny of medical records was performed regularly at six-month intervals; more careful follow-up was performed again for each 5-year calendar period $(21,22)$. Due to the follow-up efforts, the proportion of death certificate only (DCO) cases was very low, and nearly $100 \%$ of the died-of-cancer cases had DCN records. Therefore, all new patients or patients who had died that were diagnosed and/or treated in Qidong, or even outside of Qidong, were completely recorded and their outcomes were ascertained.

Cancer classification, coding and case confirmation. Due to the development of the International Classification of Diseases (ICD), three versions (8th, 9th, 10th) that were revised by the World Health Organization during the past four decades, ICD-8, ICD-9 and ICD-10, were used for the coding practice in the Qigong Cancer Registry. In the current study, the cancer data have been reclassified and recoded according to the ICD-10 criteria. The cut-off for the final follow-up for survival status was April 2012. The proportion of morphological verification (MV) was 39.94\% (37,052/92,780), with a lower DCO rate of $0.23 \%$. The survival duration of each case was determined as the time difference from the date of initial diagnosis to the date of mortality due to cancer, date of death due to other diseases or date when the patient was lost to follow-up, and the date of closing for those still alive.

Survival analysis. Cumulative observed survival rate and relative survival rate were calculated. Relative survival rate was defined as the ratio of the observed survival rate to the expected rate that was based on a group of people in the general population similar to the patient group with respect to gender, age and calendar period of observation. This means that the survival of patients was adjusted to the normal life expectancy of the general population of the same age (23). The all-cause mortality and the life table data of the general population, which contains the probability of death and the life expectancy for single year age-groups for both sexes, for the relevant calendar years, was generated from the Qidong Vital Registry (Qidong All-Death-Cause Registration) (19,24). This measure made the relative survival rate an estimate of the chance of surviving the effects of cancer (25-28). The observed survival and relative survival rates were computed with 6 age groups (15-34, 35-44, 45-54, 55-64, 65-74 and 75+) and 9 calendar periods (1972, 1973-1977, 1978-1982, 1983-1987, 1988-1992, 1993-1997, 1998-2002, 2003-2007 and 2008-2011) using Hakulinen's method performed using the SURV3.01 software developed at the Finnish Cancer Registry, including the statistical tests $\left(\mathrm{H}_{0}-\mathrm{H}_{2}\right.$ equal vs. unequal hazards), derived from the software (26); $\mathrm{P}<0.05$ was considered statistically significant.

\section{Results}

The basic characteristics of cancer data and their quality indices. A total of 92,780 cases of cancer were registered between January 1, 1972 and December 31, 2011, with a crude incidence rate of 206.39 per 100,000 , and an age standardized rate by world population $\left(\mathrm{ASR}_{\mathrm{W}}\right.$ ) of 159.11 per 100,000 (213.69 for males and 109.99 for females). The quality indices used for cancer cases are the percent of DCO, percent of morphological verification and the ratio of mortality to incidence. These quality indices by site have been described in our previous studies $(18,24)$. Briefly, as presented in Table I, the age-group distribution and the quality indices for the main sites of the cancer were, in rank order: liver, stomach, lung, colon-rectum, oesophagus, breast, pancreas, blood (leukaemia), brain 
Table I. Case age distribution and quality indices of the major sites of cancers in Qidong, 1972-2011.

\begin{tabular}{|c|c|c|c|c|c|c|c|c|c|c|c|c|c|c|}
\hline \multirow[b]{2}{*}{ Site } & \multirow[b]{2}{*}{ ICD-10 } & \multicolumn{7}{|c|}{ Age, years and no. of cases } & \multirow[b]{2}{*}{ Total } & \multicolumn{2}{|c|}{ DCO } & \multicolumn{2}{|c|}{ MV } & \multirow[b]{2}{*}{ M:I } \\
\hline & & $0-14$ & $15-34$ & $35-44$ & $45-54$ & $55-64$ & $65-74$ & $75+$ & & No. & $\%$ & No. & $\%$ & \\
\hline Oesophagus & C15 & 1 & 24 & 81 & 392 & 995 & 1,538 & 1,383 & 4,414 & 11 & 0.25 & 1,533 & 34.73 & 0.95 \\
\hline Stomach & $\mathrm{C} 16$ & 2 & 308 & 879 & 1,993 & 3,716 & 4,807 & 3,696 & 15,401 & 29 & 0.19 & 8,550 & 55.52 & 0.89 \\
\hline Colon-rectum & $\mathrm{C} 18-21$ & 2 & 183 & 373 & 749 & 1,251 & 1,774 & 1,703 & 6,035 & 2 & 0.03 & 4,819 & 79.85 & 0.75 \\
\hline Liver & C22 & 64 & 2,602 & 6,819 & 7,673 & 5,606 & 3,612 & 2,022 & 28,398 & 88 & 0.31 & 3,797 & 13.37 & 0.96 \\
\hline Pancreas & $\mathrm{C} 25$ & 3 & 42 & 142 & 347 & 732 & 1,111 & 902 & 3,279 & 7 & 0.21 & 774 & 23.6 & 0.95 \\
\hline Lung & C33-34 & 5 & 128 & 513 & 1,695 & 3,852 & 5,411 & 3,736 & 15,340 & 41 & 0.27 & 1,951 & 12.72 & 0.93 \\
\hline Breast $^{\mathrm{a}}$ & $\mathrm{C} 50$ & 1 & 180 & 761 & 1,097 & 720 & 417 & 276 & 3,452 & 0 & 0 & 3,212 & 93.05 & 0.51 \\
\hline Cervix & C53 & 3 & 62 & 191 & 263 & 281 & 229 & 182 & 1,211 & 0 & 0 & 1,089 & 89.93 & 0.72 \\
\hline Bladder & C67 & 2 & 22 & 52 & 143 & 345 & 474 & 581 & 1,619 & 0 & 0 & 1,158 & 71.53 & 0.68 \\
\hline $\mathrm{B}$ and $\mathrm{CNS}$ & C70-72 & 104 & 189 & 221 & 384 & 377 & 350 & 160 & 1,785 & 6 & 0.34 & 480 & 26.89 & 0.9 \\
\hline NHL & C82-85/96 & 48 & 133 & 146 & 228 & 337 & 361 & 219 & 1,472 & 0 & 0 & 1,468 & 99.73 & 0.85 \\
\hline Leukaemia & C91-95 & 221 & 402 & 242 & 264 & 303 & 328 & 170 & 1,930 & 4 & 0 & 1,921 & 99.53 & 0.93 \\
\hline All sites & $\mathrm{C} 00-96$ & 538 & 4,897 & 11,150 & 16,633 & 20,301 & 22,429 & 16,832 & 92,780 & 212 & 0.23 & 37,052 & 39.94 & 0.88 \\
\hline
\end{tabular}

ancludes 32 cases of male breast cancer. DCO, death certificate only; MV, morphological verification; B and CNS, brain and central nervous system; NHL, non-Hodgkin's lymphoma; ICD, International Classification of Diseases; M:I, mortality: incidence.

and central nervous system (B and CNS), bladder, blood [non-Hodgkin's lymphoma (NHL)] and cervix.

Observed survival rate and relative survival rate by site. Table II shows the 1-, 5-, 10-, 20- and 30-year observed survival and relative survival rates by site. For all sites combined, the observed survivals were 29.23, 13.18, 9.98, 7.09 and $5.00 \%$, and the relative survivals were $30.29,15.80$, $14.52,15.90$ and $18.67 \%$, respectively. The highest 5-year observed survival rate among the major cancers was found to be the female breast $(58.75 \%)$, followed by the cervix $(42.66 \%)$ and bladder (35.98\%); the poorest 5-year observed survival rate was liver $(4.26 \%)$, and then pancreas $(4.87 \%)$ and lung (5.15\%). For 5-year relative survival, the three sites with the best rates were the female breast $(63.12 \%)$, bladder $(50.06 \%)$ and cervix $(48.82 \%)$; the worst rates were for the liver $(4.69 \%)$, pancreas $(6.30 \%)$ and lung $(6.61 \%)$. The 20 -year observed survival rates from highest to lowest were female breast $(38.30 \%)$, cervix $(23.82 \%)$, bladder $(18.37 \%)$ and colon-rectum cancer (15.57\%), NHL (9.54\%), stomach (6.63\%) and B and CNS cancer (4.66\%), leukaemia (2.90\%), pancreas $(2.66 \%)$, lung $(2.39 \%)$, liver $(2.15 \%)$ and oesophageal cancer $(1.83 \%)$. The 20 -year relative survival rates were as follows: bladder (76.39\%), female breast $(56.36 \%)$, cervix $(53.09 \%)$, colon-rectum $(45.53 \%)$ and stomach cancer (21.96\%), NHL (19.37\%), pancreas $(9.27 \%)$, lung $(8.55 \%)$, oesophagus $(8.30 \%)$ and $\mathrm{B}$ and CNS cancer $(7.55 \%)$, leukaemia $(4.35 \%)$ and liver cancer $(3.40 \%)$.

Five-year observed survival and relative survival by sex. In general, for all sites combined, females had higher observed and relative survival (19.32 and $22.71 \%$, respectively) than males (9.63 and $11.68 \%$, respectively). This outcome reflects the higher proportion of female site-specific cancer types, such as cancer of the female breast and cervix, with higher survival rates. Table III reveals minimal differences between the sexes in terms of 5-year observed and relative survival rates for the major cancer sites. For site-specific cancers, bladder cancer and stomach cancer had lower survival rates in females compared with males, whereas for cancers of the liver, lung, oesophagus, B and CNS and NHL, survival rates were higher in females than males.

Five-year observed survival and relative survival by age group. Table IV shows the 5-year observed and relative survival by age group $(15-34,35-44,45-54,55-64,65-74$, and $75+)$ for all the major cancer sites. Relatively higher survival rates were observed in younger patients (15-34,35-44) compared with older patients $(65-74,75+)$, particularly for sites including the stomach, lung, pancreas, B and CNS, blood (NHL) and cervix. Cancer of the oesophagus, female breast and bladder had higher survival in middle-aged groups (45-54,55-64) than at other age groups. Liver cancer had relatively stable low survival rates at each age group. For all sites combined, middle-aged patients had the highest survival results of 5-year observed and relative survival rates.

Five-year observed and relative survival by period. Table $\mathrm{V}$ reveals the 5 -year observed and relative survival by calendar year for each of the main sites. The 5-year observed survival and relative survival rates in the period of 1973-1977 were used as the baseline for comparison. The survival rates of stomach, lung, colon-rectum, oesophagus and female breast cancer, leukaemia, bladder cancer and NHL in the most recent two 5-year calendar periods showed improvement compared with previous periods. The survival rate of liver cancer has shown modest improvement since the 1978-1982 period, although the total survival rate remains poor. The survival rate for pancreatic cancer is the only one exhibiting no real change during these periods. 
Table II. Observed survival rate and relative survival rate by site.

\begin{tabular}{|c|c|c|c|c|c|c|c|c|c|c|}
\hline \multirow[b]{2}{*}{ Site } & \multicolumn{5}{|c|}{ Observed survival rate, $\%$} & \multicolumn{5}{|c|}{ Relative survival rate, $\%$} \\
\hline & 1-year & 5-year & 10-year & 20-year & 30-year & 1-year & 5-year & 10-year & 20-year & 30-year \\
\hline Liver & 15.18 & 4.26 & 2.79 & 2.15 & 1.73 & 15.47 & 4.69 & 3.41 & 3.40 & 4.02 \\
\hline Stomach & 33.82 & 14.18 & 10.35 & 6.63 & 4.19 & 35.43 & 18.13 & 17.50 & 21.96 & 32.84 \\
\hline Lung & 16.69 & 5.15 & 3.75 & 2.39 & 2.03 & 20.65 & 6.61 & 6.44 & 8.55 & 18.84 \\
\hline Colon-rectum & 52.91 & 27.83 & 21.59 & 15.57 & 10.19 & 55.48 & 35.58 & 35.85 & 45.53 & 54.40 \\
\hline Oesophagus & 20.92 & 5.28 & 3.39 & 1.83 & 1.61 & 22.19 & 7.20 & 6.58 & 8.30 & 21.75 \\
\hline Female breast & 83.61 & 58.75 & 48.56 & 38.30 & 29.19 & 84.76 & 63.12 & 56.81 & 56.36 & 62.59 \\
\hline Pancreas & 12.69 & 4.87 & 3.76 & 2.66 & 1.28 & 13.34 & 6.30 & 6.47 & 9.27 & 10.65 \\
\hline Leukaemia & 23.00 & 7.47 & 3.80 & 2.90 & 2.90 & 23.43 & 8.23 & 4.64 & 4.35 & 5.26 \\
\hline $\mathrm{B}$ and $\mathrm{CNS}$ & 25.20 & 10.91 & 8.29 & 4.66 & 4.12 & 25.73 & 12.15 & 10.37 & 7.55 & 9.09 \\
\hline Bladder & 59.91 & 35.98 & 26.91 & 18.37 & 12.24 & 64.07 & 50.06 & 52.42 & 76.39 & 115.75 \\
\hline NHL & 32.48 & 15.78 & 12.76 & 9.54 & 7.63 & 33.49 & 18.46 & 17.79 & 19.37 & 22.44 \\
\hline Cervix & 64.30 & 42.66 & 35.16 & 23.82 & 12.75 & 65.85 & 48.82 & 48.08 & 53.09 & 60.33 \\
\hline All sites & 29.23 & 13.18 & 9.98 & 7.09 & 5.00 & 30.29 & 15.80 & 14.52 & 15.90 & 18.67 \\
\hline
\end{tabular}

B and CNS, brain and central nervous system; NHL, non-Hodgkin's lymphoma.

Table III. Five-year observed survival rate and relative survival rate by sex.

\begin{tabular}{|c|c|c|c|c|c|c|c|c|}
\hline \multirow[b]{2}{*}{ Site } & \multicolumn{4}{|c|}{ Male } & \multicolumn{4}{|c|}{ Female } \\
\hline & OS & $2 * \mathrm{SE}_{\mathrm{OS}}$ & $\mathrm{RS}$ & $2 * \mathrm{SE}_{\mathrm{RS}}$ & OS & $2 * \mathrm{SE}_{\mathrm{OS}}$ & $\mathrm{RS}$ & $2 * \mathrm{SE}_{\mathrm{RS}}$ \\
\hline Liver & 4.06 & 0.29 & 4.47 & 0.32 & 4.87 & 0.55 & 5.37 & 0.61 \\
\hline Stomach & 14.40 & 0.74 & 18.67 & 0.95 & 13.80 & 0.96 & 17.21 & 1.20 \\
\hline Lung & 4.68 & 0.43 & 6.14 & 0.57 & 6.36 & 0.82 & 7.78 & 1.00 \\
\hline Colon-rectum & 27.43 & 1.78 & 35.96 & 2.33 & 28.20 & 1.73 & 35.24 & 2.16 \\
\hline Oesophagus & 5.03 & 0.84 & 6.92 & 1.16 & 5.82 & 1.32 & 7.77 & 1.76 \\
\hline Female Breast & - & - & - & - & 58.75 & 1.81 & 63.12 & 1.95 \\
\hline Pancreas & 4.67 & 1.05 & 6.14 & 1.38 & 5.12 & 1.21 & 6.47 & 1.53 \\
\hline Leukaemia & 7.39 & 1.72 & 8.28 & 1.92 & 7.58 & 1.91 & 8.19 & 2.06 \\
\hline $\mathrm{B}$ and $\mathrm{CNS}$ & 8.87 & 1.89 & 10.12 & 2.15 & 13.58 & 2.59 & 14.69 & 2.80 \\
\hline Bladder & 36.95 & 2.92 & 52.02 & 4.11 & 32.44 & 5.44 & 43.37 & 7.28 \\
\hline NHL & 15.19 & 2.51 & 18.02 & 2.98 & 16.72 & 3.35 & 19.14 & 3.84 \\
\hline Cervix & - & - & - & - & 42.66 & 3.01 & 48.82 & 3.44 \\
\hline All sites & 9.63 & 0.26 & 11.68 & 0.31 & 19.32 & 0.45 & 22.71 & 0.53 \\
\hline
\end{tabular}

$2 * \mathrm{SE}_{\mathrm{OS}}$, twice the standard error of $\mathrm{OS} ; 2^{*} \mathrm{SE}_{\mathrm{RS}}$, twice the standard error of RS. OS, observed survival rate; RS, relative survival rate; $\mathrm{B}$ and $\mathrm{CNS}$, brain and central nervous system; NHL, non-Hodgkin's lymphoma.

\section{Discussion}

The current study used 4 decades of population-based data from a registry to analyse cancer survival, updated for the outcomes of patients with cancer from the Qidong population, which collectively reflects the long-term trends of cancer survival in a rural area that has recently undergone regional economic development, and subsequent improvements of comprehensive treatment regimes and changes in local health care and service. The present authors hope these data will provide important information for further optimizing current therapies and policy.

Differences in cancer survival reported from any hospital-based observation between or within countries may not be used directly for comparison due to limitations of the number of patients receiving various cancer therapies, or variations in the availability, accessibility and the treatments from different health service practices. Therefore, the cancer survival estimated from hospital and clinical trial settings at best reflects the selective experiences of groups of patients in 


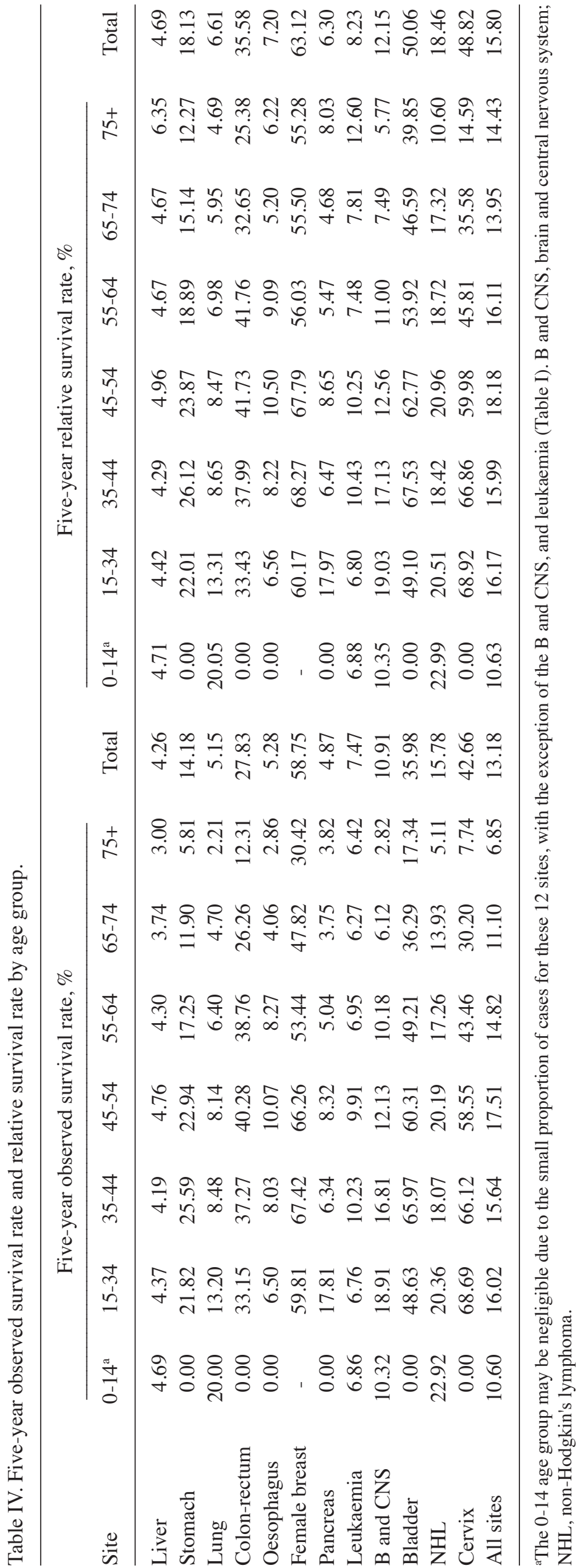




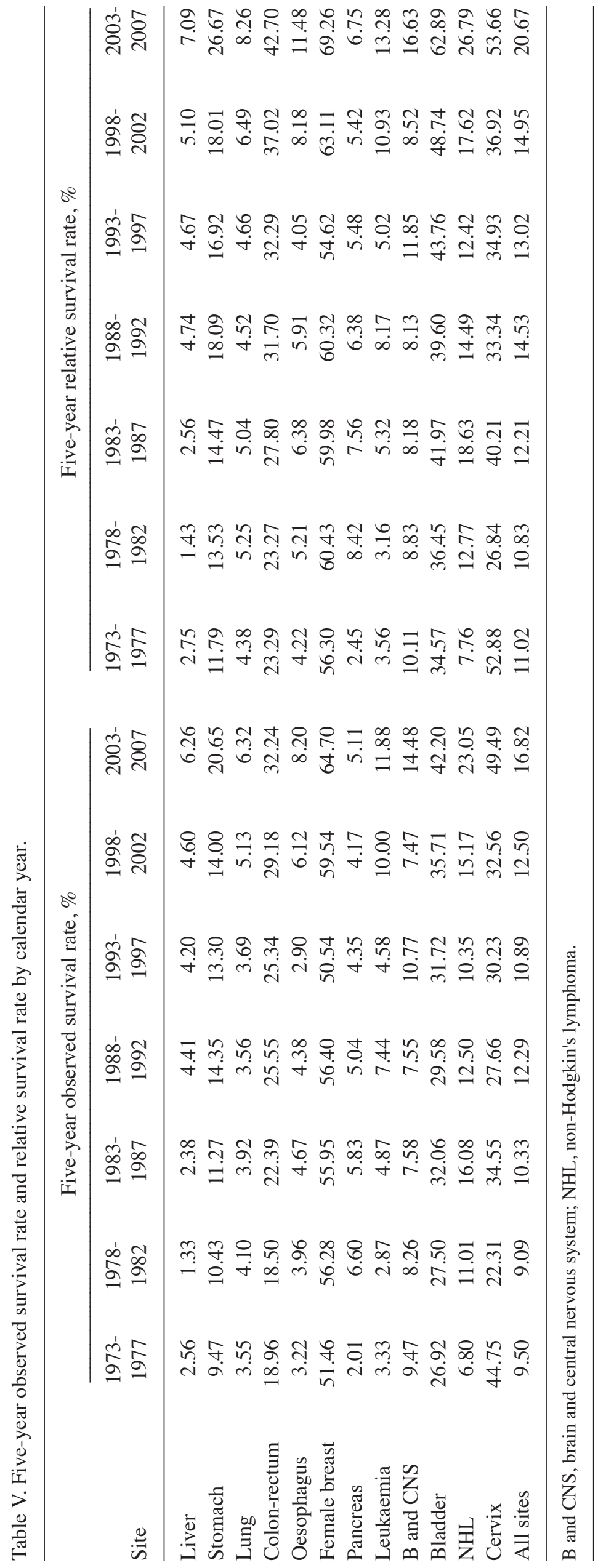


specific settings, and cannot be generalized as reflecting the overall efficiency of the cancer health services in a given region or country $(7)$.

For international comparisons of cancer survival, only the estimates of population-based survival based on all patients with cancer diagnosed by all means in a geographical region or country are recommended $(12,13)$. In European countries, this estimation has been performed since the 1990s, and the results have been published in the EUROCARE study series $(5,11,29)$, and other journals (30-33). In Asian countries, reports on cancer survival from population-based registries have increased since the beginning of this century (8); the majority of them report regional data (13,34-37). There have been few studies referring to population-based cancer survival in mainland China. Previous studies have reported on population-based cancer survival in Shanghai (38) and Zhejiang (39); however, these studies primarily focused on a certain or some cancer sites over a short time period. In Taiwan, the survival rates for epithelial ovarian cancer and uterine cancer were reported based upon data from a population-based registry $(40,41)$.

The data from 40 years of population-based registration have provided the opportunity for the estimation of long-term cancer survival in a rural area in China. At present, studies from population-based settings referring to 20-year or 30-year observed or relative survivals are limited. Germany has described the 5- and 10-year relative survivals for 24 common cancer types in the 1990-1992 cohort, and the 2000-2002 period (42), and by further follow-up, site-specific survival for tumour types such as pancreatic cancer was evaluated (43). The 5- and 10-year relative survival of patients with chronic myelocytic leukaemia from the Surveillance, Epidemiology, and End Results (SEER) Program of the United States in 1973-2004 were reported to show a dramatic increase in long-term survival of younger patients (44). Korea has reported the 5- and 10-year relative survivals for the 19 most common cancer types from 1993-2007 (45) using 8 population-based cancer registry databases. A population-based study of long-term outcomes with the 5-, 15- and 25-year overall survival of patients with head and neck cancer were reported from a Canadian province (46). More recently, long-term relative survival data among testicular germ cell tumour (TGCT) patients diagnosed in Norway between 1953 and 2012, was reported showing patients with TGCTs diagnosed prior to 1980 or after age 40 had lower relative survival (47). Almost all these papers are from developed countries or areas; such studies rarely emanate from undeveloped areas.

The 5-year relative survival rate is a common index for the estimation of cancer outcome, and is regarded as almost equivalent to a cure for a specific cancer. The index of 20-year or 30-year relative survival is not widely used as i) long-term data are challenging to obtain, and ii) high durations of relative survival may be affected not only by the biological characteristics of the cancer but also by the survival probability (27), otherwise known as the life expectancy of the patient following diagnosis and treatment. Due to the ratio of the observed survival rate to this expected rate, the relative survival rate may occasionally increase with the survival year, that is, the 30 -year relative survival rate might be even higher than the 20-year relative survival rate. In the current data, for instance, the 20-year relative survival rate of patients with bladder is
$76.39 \%$, and the 30 -year relative survival rate is $115.75 \%$ (Table II), meaning that those patients who survived $>30$ years have a higher survival than the comparable population.

The survival status of any patients with cancer may be affected by numerous risk factors, particularly for elderly patients. In the present series, we identified that cancer affecting the female breast, cervix, bladder and colon-rectum has higher observed and relative survival rates compared with other cancer sites. Oesophageal cancer had the lowest 20-year observed survival, followed by cancers of the liver, lung and pancreas; liver cancer had the poorest 20 -year relative survival, followed by leukaemia, B and CNS and oesophageal cancer, reflecting the possible competing risks from other causes of mortality (48) or the longevity factors of the different patient populations. The present study will primarily focus on the 5-year relative survival rate for further site-specific comparisons.

Liver cancer was the most prevalent type of cancer with an $\mathrm{ASR}_{\mathrm{W}}$ of 50.71 per 100,000 and a cumulative risk of $5.15 \%$ for the forty-year period in Qidong. It is the fourth most common cancer in China $(14,49)$, and fifth common cancer site in the world (50). As this cancer type is rare in developed countries (51), most of the survival reports associated with liver cancer are from developing countries $(6,7,13,52)$. The survival for patients with liver cancer is usually poor. A report from Taiwan revealed that the mean survival time of 3,850 patients with liver cancer was $\sim 1.8$ years (53). An American study demonstrated that the 5-year relative survival was $3 \%$ in the period from $1975-1977,5 \%$ from $1987-1989$ and $18 \%$ from 2003-2009 (50). A comparison study with data from European countries and the Philippines has shown that the 5-year relative survival rates for this cancer type in 1995-1999 were 9.1 and $5.3 \%$, respectively, indicating the discrepancy between developed and undeveloped countries (54). In the current study, the 5 -year relative survival for liver cancer was around $2 \%$ in the 1970 's, about $2-3 \%$ in 1980 's, $4-5 \%$ in the 1990 's, and $5-7 \%$ in the early $2000 \mathrm{~s}$, showing low rates but with slight improvement. There were no significant differences between the sexes for the relative 5-year, 10-year and 15-year survival rates. No significant differences were observed among the 15-34, 35-44, 45-54, 55-64 and 65-74 age groups, but the patients with liver cancer aged $>75$ had higher 5-year relative survival compared with other ages.

Stomach cancer had an $\mathrm{ASR}_{\mathrm{W}}$ of 25.59 per 100,000 and a cumulative risk of $3.10 \%$ over the 4 decades. It is the most common cancer type in China $(14,49)$ and the second most common cancer site in the world (50). According to previous global reports, the incidence of stomach cancer has been decreasing over the past few decades due to changes in food preservation, and improved survival due to early detection $(55,56)$, or perhaps improvement of therapies. In a recent Swedish study, the 5-year relative survival rate for gastric cardia adenocarcinoma was reported to be $11.1 \%$ in 1990-1999 and $14.3 \%$ in 2000-2008, with higher survival rates among males and younger patients. For gastric non-cardia adenocarcinoma, the 5-year relative survival rate was $19.0 \%$ in 2000-2008 and $20.2 \%$ in 1990-1999, with no differences between sexes, and among age groups (32). In the present data, an improvement in 5-year relative survival was identified during the 40-year period, increasing from $11.79 \%$ in $1973-1982$ to $26.67 \%$ in 
2003-2007. Middle-aged patients (35-44 and 45-54 years) had relatively higher 5-year observed survivals $(21.77 \%$ and $18.63 \%$, respectively) than those under 35 years $(16.13 \%)$ and those aged 55-64 (12.61\%), 65-74 (7.99\%) and aged $>75$ (2.94\%). These relatively poor results are in accordance with a previous report (57) that compared survival between patients with stomach cancer in China and the United States, indicating that Chinese patients have poorer outcomes than US patients due to larger tumours and a later stage at presentation.

Lung cancer was the third major cancer site with an $\mathrm{ASR}_{\mathrm{W}}$ of 25.41 per 100,000 and a cumulative risk of $3.22 \%$ on average over the forty years, although it has recently overtaken liver cancer and stomach cancer as the most frequent cancer site in Qidong. It was also the most common cancer type for the period between 2003 and 2007 in China (49), and globally $(50,58)$; both in rural areas such as Qidong $(27,59)$ and urban areas including Shanghai $(14,60)$. The increasing trend of the worldwide burden of lung cancer likely results from smoking (accounting for $80 \%$ of cases in males and $\geq 50 \%$ in females), and outdoor air pollution (61), but the relatively high burden of lung cancer in females may also reflect indoor air pollution from unventilated coal-fuelled stoves and from cooking fumes in China, India and other regions still reliant on biomass fuels $(50,62)$. Lung cancer incidence rates are decreasing in the majority of Western countries, whereas in China and other countries in Asia and Africa, lung cancer incidence rates are increasing (18,22,49-51). The improvement in lung cancer survival in recent decades has been minimal, with 5-year survival rates of 13\% in 1975-1977 and 1984-1986, and $16 \%$ in 1999-2005 (63). In the present series, lung cancer has increased with an annual percent change rate (ASRw) of $2.21 \%$ since the 1970s; however, the relative survival rate shows no major improvements, with observed survival rates of $4.38 \%$ from 1973-1977 and 4.69\% from 1998-2003, with an elevation to $8.26 \%$ in $2003-2007$. A younger patient age was associated with improved outcomes, with observed survival of $13.31 \%$ at aged $15-34$ and $4.69 \%$ in the age group $>75$ years.

Colorectal cancer (CRC) was the fourth most common site with an $\mathrm{ASR}_{\mathrm{W}}$ of 9.80 per 100,000 and a cumulative risk of $1.15 \%$ during the 40 -year period in Qidong. Globally, CRC is the third most prevalent cancer type for males and the second most common for females (58). It is a cancer type that has increased in the majority of countries since the 1950s, and the incidence rates among males in the Czech Republic and Japan have already exceeded the peak of incidence observed in the United States, Canada and Australia, where rates are declining or stabilizing (50). However, the survival rate for patients with this cancer type has also improved during previous decades. According to a recent report examining Danish patients, the overall 5-year survival improved from $39 \%$ to a predicted survival of $46 \%$ for those diagnosed in 2009-2011, corresponding to a 5-year adjusted mortality rate ratio of 0.76 compared with 2000-2002 (64). In China, CRC has been reported to be among the three most prevalent forms of cancer, after lung and stomach cancer (49); however, a recent study suggested that it was the fifth most common cancer site (14). In Zhejiang, China, where CRC is prevalent, the 5-year relative survival rate for patients with CRC was $58.73 \%$, with significant variation between different age groups, from $63.07 \%$ at $35-44$ years to $47.41 \%$ in those aged $>75$ (39). In the current series, the survival rates of patients with CRC have slightly increased, but remain very poor compared with the relative survival rates of 50\% in 1970-1977 and 66\% in 2005-2011 for patients with CRC in the United States (65). There is even a disparity between the survival rates in Zhejiang and Qidong, with 5-year relative survival rates of 58.73 vs. $35.58 \%$, which perhaps reflects the difference in the treatment opportunities between urban and rural areas.

Oesophageal cancer (OC) ranked as the fifth most prevalent cancer type, with an $\mathrm{ASR}_{\mathrm{W}}$ of 7.08 per 100,000 and a cumulative risk of $0.88 \%$ in the period from 1972-2011 in Qidong. Worldwide, this cancer is more common among males (seventh most common cancer site) than females (below the tenth most common site), and had the highest incidence rates in Southern and Eastern Africa and Eastern Asia, and the lowest rates in Western and Middle Africa and Central America (58). China is a relatively high incidence area for OC, ranking sixth in the world according to the 2003-2007 statistics (49), and ranking third in China according to a more recent estimation (14). A recent review indicates that the OC survival is poor for all groups, and is significantly poorer in black patients compared with white patients; the 5-year relative survival for 2002-2008 from 18 SEER geographic areas was $16.9 \%$ (66). A Swedish study revealed an improved 5-year relative survival for OC, increasing from $12.5 \%$ in $1990-1999$ to $14.6 \%$ in $2000-2008$ (32). However, a recent study in the United Kingdom from a population-based cohort reveals that following oesophagectomy the 5-year survival of oesophageal adenocarcinoma may be $65.1 \%$ (114/175), demonstrating an improved outcome for patients with early-stage OC (67). In the present series, the 5-year relative survival was $7.20 \%$, and slightly higher in females (7.77\%) compared with males $(6.92 \%)$. There was a higher relative survival in the 45-54 age group (10.50\%) compared with other age groups (5.20-9.09\%), and the relative survival of OC has improved from $4.22 \%$ from $1973-1977$ to $11.48 \%$ from 2003-2007. The survival rates for patients with OC are lower than the average rates for urban (19.1\%) and rural areas (21.2\%) during the years 2003-2005 in China (68).

Breast cancer ranked sixth with an $\mathrm{ASR}_{\mathrm{W}}$ of 6.13 per 100,000 and a cumulative risk of $0.64 \%$ during the 40 years. In females, breast cancer was the fourth most common cancer site, with an $\mathrm{ASR}_{\mathrm{W}}$ of 11.78 per 100,000 in Qidong. Female breast cancer (FBC) has been the most common cancer site in women worldwide, with rapidly increasing trends in many Western countries since the late 1980s (50). It is also the commonest site in females in China $(14,49)$. FBC has higher survival rates than other forms of cancer. It is hypothesized that the decrease in breast cancer mortality during the past two decades in Germany and the US was primarily due to early detection and advances in treatment, with 5-year relative survival of localized breast cancer of $98.7 \%$ in Germany and $97.3 \%$ in the US between 2005 and 2008 (69). An international comparison reveals that there were no major differences in survival between European countries, with 5-year relative survival rates of $90-99 \%$ for the patients with stage I and II disease (70). At the population-based level, the survival rates of female patients with breast cancer were $75 \%$ in $1975-1977$, $84 \%$ in $1987-1989$ and $91 \%$ in $2005-2011$ from 9 SEER areas in the US (65). A Singapore-Malaysia hospital-based breast cancer study revealed that ethnicity is independently 
associated with poorer survival, with 5-year overall survival rates of $75.8 \%$ in Chinese females, $68.0 \%$ in Indian patients, and $58.5 \%$ in Malay patients with breast cancer (1). However, the data in the present study revealed reduced 5-year relative survival rates for female patients with breast cancer ranging from 50.63 to $69.26 \%$ among time periods, and $55.28-68.27 \%$ among age groups, reflecting the wide gap in the early detection and treatment for this disease in this rural area.

The cancer types that were ranked seventh to twelfth most common for the 40-year period were pancreatic cancer, leukaemia, B and CNS and bladder cancer, NHL and cervical cancer. Pancreatic cancer is a rapidly progressing disease with a poor prognosis, and the improvement in 5-year survival over time has been very limited, with rates of 2.0, 2.1, 3.4 and $3.8 \%$ for the periods $1998-2000,2001-2003,2004-2006$ and 2007-2009, respectively, according to a study from Denmark (71). Slight improvements in 5-year relative survival of $10.7 \%$ in Germany and $10.3 \%$ in the United States were observed from 1997-2010 (65). Generally, the outcome is very poor for pancreatic cancer, irrespective of whether the country is wealthy or poor, or whether the region is urban or rural. In Shanghai, for instance, the 5-year survival was $4.1 \%$ in 2004-2009 (38), whereas in the current data, the 5-year observed and relative survival in 1972-2011 were 4.87 and $6.30 \%$, respectively. The largest improvements in survival have been observed from an American cancer statistical report, for leukaemia (from $34 \%$ in $1975-1977$ to $59 \%$ in $2003-2009$ ), NHL (from 47 to $71 \%$, respectively), and B and CNS (from 22 to $35 \%$, respectively), whereas bladder and cervical cancer have shown the least improvement (from 72 to $80 \%$, and from 69 to $69 \%$, respectively) (51). A study from the UK observed the ethnic differences in cancer survival, revealing that male South Asian patients experienced a higher excess mortality than non-South Asians for NHL, with 5-year survival rates of 48.4 vs. $50.3 \%$ in $1986-1995$, and of $57.2 \%$ vs. $57.8 \%$ in $1996-2004$, respectively (72). For the 5-year relative survival in patients with B and CNS cancer in Qidong, the present study identified no major changes for earlier time periods (8.13-11.85\%), but it has improved recently, with a rate of $16.63 \%$ in $2003-2007$. In Korea, bladder cancer had a relatively high 5-year relative survival rate of $80.2 \%$ in 2006-2010 (36); whereas in China, this rate was $67.3 \%$ in 2003-2005 (68). Although the 5-year relative survival of bladder cancer was lower in our data, the outcomes have improved from $34.57 \%$ in $1973-1977$, to $39.60 \%$ in $1988-1992$ and to $62.89 \%$ in $2003-2007$. For cervical cancer, the 5-year relative survival was $48.82 \%$, fell steeply with age and improved notably in 2003-2007 (53.66\%), but was lower than the results from South Korea (79\%) and Singapore (76\%) (13). The 5-year relative survival of patients with leukaemia in Qidong during the 40-year study period was 8.23 and $13.28 \%$ in $2003-2007$, which is very low as compared with that in the United States (50\%) (73), and in the European countries $(42.4 \%)$, but higher than that in the Philippines $(2.7 \%)(54)$. The 5-year survival outcomes of leukaemia are varied worldwide with comparable poor results (2005-2009) identified in registries in India (6.0\%), Libya (6.2\%), and Jordan (7.1\%); improved results have been reported in Cyprus (61.3\%), Belgium (59.4\%) and Sweden (59.2\%) (12).

Stage is the most important factor determining survival, as optimal and 'curative' treatment may only be offered to patients diagnosed at an early enough stage to benefit from it (74). In a SEER study (75), the 5-year relative survival for those diagnosed at early stage (stage I) was very good (100\% for all ethnicities combined), but if metastatic disease is diagnosed (stage IV), survival drops rapidly, revealing the effect of early-stage diagnosis on the prognosis. However, in the current population-based cancer registration series, stage information was sporadically available, which is a common problem in population-based cancer registries worldwide (76). This may restrict our stage analysis but does not limit the assessment of the general changes in the survival rates, particularly the long-term survival rates of cancers in the population-based covered area. Another limitation of the present study is the possible errors in diagnosis in the first year of registration (77), but this effect would be minimal over the 40-year dataset, and for period comparison, the use of 1973-1977 data should be an optimum baseline of survival.

In conclusion, survival analyses from the present updated dataset, now spanning four decades, have described the short and long-term survival effects for the most prevalent cancer sites. Such population-based analyses may aid the evaluation of the current and future impacts of comprehensive health services on cancer detection and treatment in Qidong, and other undeveloped areas in China. From the present findings, we have revealed that there is a large gap in cancer survival rates between the Qidong region and other settings from developed areas in China and in developed countries. The improving trends in survival of most cancers that have gradually occurred in Qidong during the past four decades may accelerate with the advent of precision oncology for screening, early diagnosis and treatment in an efficient, effective and affordable manner for all populations, and particularly underserved populations. Greater effort is required to improve the survival rates of all cancer types.

\section{Acknowledgements}

The present study was supported by The Qidong Cancer Registry in which the data were compulsorily reported by health workers in the Qidong Health Care System. The authors would like to thank the staff of the 12 towns in Qidong for undertaking the case finding and follow-up. The authors would also like to thank Professor Thomas W. Kensler of Johns Hopkins Bloomberg School of Health, and University of Pittsburgh, USA for his useful comments and language editing.

\section{References}

1. Bhoo-Pathy N, Hartman M, Yip CH, Saxena N, Taib NA, Lim SE, Iau P, Adami HO, Bulgiba AM, Lee SC and Verkooijen HM: Ethnic differences in survival after breast cancer in South East Asia. PLoS One 7: e30995, 2012.

2. Fang YJ, Wu XJ, Zhao Q, Li LR, Lu ZH, Ding PR, Zhang RX Kong LH, Wang FL, Lin JZ, et al: Hospital-based colorectal cancer survival trend of different tumor locations from 1960s to 2000s. PLoS One 8: e73528, 2013.

3. Wan S, Lai Y, Myers RE, Li B, Palazzo JP, Burkart AL, Chen G, Xing $\mathbf{J}$ and Yang $\mathrm{H}$ : Post-diagnosis hemoglobin change associates with overall survival of multiple malignancies-results from a 14-year hospital-based cohort of lung, breast, colorectal, and liver cancers. BMC Cancer 13: 340, 2013.

4. Neal RD, Tharmanathan P, France B, Din NU, Cotton S, Fallon-Ferguson J, Hamilton W, Hendry A, Hendry M, Lewis R, et al: Is increased time to diagnosis and treatment in symptomatic cancer associated with poorer outcomes? Systematic review. Br J Cancer 112 (Suppl 1): S92-S107, 2015. 
5. Berrino F, Sant M, Verdecchia A, Capocaccia R, Hakulinen T and Este've J (eds): Survival of Cancer Patients in Europe: The EUROCARE Study (IARC Scientific Publications No. 132). International Agency for Research on Cancer, Lyon, France, pp1-475, 1995.

6. Sankaranarayanan R, Black R, Swaminathan R and Parkin DM (eds): Cancer Survival in Developing Countries. (IARC Scientific Publications No. 145). International Agency for Research on Cancer, Lyon, France, pp1-173, 1998.

7. Sankaranarayanan R and Swaminathan R (eds): Cancer Survival in Africa, Asia, the Caribbean and Central America. (IARC Scientific Publications No. 162). International Agency for Research on Cancer, Lyon, France, pp1-291, 2011.

8. Chia KS, Du WB, Sankaranarayanan R, Sankila R, Seow A and Lee HP: Population-based cancer survival in Singapore, 1968 to 1992: An overview. Int J Cancer 93: 142-147, 2001.

9. Raju RS, Coburn N, Liu N, Porter JM, Seung SJ, Cheung MC Goyert N, Leighl NB, Hoch JS, Trudeau ME, et al: A population-based study of the epidemiology of pancreatic cancer: A brief report. Curr Oncol 22: e478-e484, 2015.

10. Rossi S, Baili P, Capocaccia R, Caldora M,Carrani E, Minicozzi P, Pierannunzio D, Santaquilani M, Trama A, Allemani C, et al: The EUROCARE-5 study on cancer survival in Europe 1999-2007: Database, quality checks and statistical analysis methods. Eur J Cancer: Sep 6, 2015 (Epub ahead of print).

11. De Angelis R, Sant M, Coleman MP, Francisci S, Baili P, Pierannunzio D, Trama A, Visser O, Brenner H, Ardanaz E, et al: Cancer survival in Europe 1999-2007 by country and age: Results of EUROCARE-5-a population-based study. Lancet Oncol 15: 23-34, 2014.

12. Allemani C, Weir HK, Carreira H, Harewood R, Spika D, Wang XS, Bannon F, Ahn JV, Johnson CJ, Bonaventure A, et al: Global surveillance of cancer survival 1995-2009: Analysis of individual data for $25,676,887$ patients from 279 population-based registries in 67 countries (CONCORD-2). Lancet 385 977-1010, 2015.

13. Sankaranarayanan R, Swaminathan R, Brenner H, Chen $\mathrm{K}$, Chia KS, Chen JG, Law SC, Ahn YO, Xiang YB, Yeole BB, et al: Cancer survival in Africa, Asia, and Central America: A population-based study. Lancet Oncol 11: 165-173, 2010.

14. Chen W, Zheng R, Baade PD, Zhang S, Zeng H, Bray F, Jemal A, Yu XQ and He J: Cancer statistics in China, 2015. CA Cancer J Clin 66: 115-132, 2016

15. Saadatmand S, Bretveld R, Siesling S and Tilanus-Linthorst MM: Influence of tumour stage at breast cancer detection on survival in modern times: Population based study in 173,797 patients. BMJ 351: h4901, 2015.

16. Thein HH, Khoo E, Campitelli MA, Zaheen A, Yi Q, De P and Earle CC: Trends in relative survival in patients with a diagnosis of hepatocellular carcinoma in Ontario: A population-based retrospective cohort study. CMAJ Open 3: E208-E216, 2015.

17. Wang R, Wang MJ and Ping J: Clinicopathological features and survival outcomes of colorectal cancer in young versus elderly: A population-based cohort study of seer 9 registries data (1988-2011). Medicine (Baltimore) 94: e1402, 2015.

18. Chen JG, Zhu J, Parkin DM, Zhang YH, Lu JH, Zhu YR and Chen TY: Trends in the incidence of cancer in Qidong, China, 1978-2002. Int J Cancer 119: 1447-1454, 2006.

19. Chen JG, Peto R, Sun ZT and Zhu YR (eds): Feasibility of a prospective study of smoking and mortality in Qidong, China. O'neill IK, Chen J, Bartsch H (edition). Relevance to human cancer of $\mathrm{N}$-nitroso compounds, tobacco and mycotoxins (IARC Scientific Publications No. 105). International Agency for Research on Cancer, Lyon, France, pp502-e506, 1991

20. Wei KR, Chen WQ, Zhang SW, Liang ZH, Zheng RS and Ou ZX: Cancer registration in the Peoples Republic of China. Asian Pac J Cancer Prev 13: 4209-4214, 2012.

21. Parkin DM, Whelan SL, Ferlay J, Teppo L and Thomas DB (eds): Cancer Incidence in Five Continents Vol. VIII. (IARC Scientific Publications No. 155). International Agency for Research on Cancer, Lyon, France, pp1-781, 2002.

22. Forman D, Bray F, Brewster DH, Gombe Mbalawa C, Kohler B Piñeros M, Steliarova-Foucher E, Swaminathan R and Ferlay J (eds): Cancer Incidence in Five Continents Vol. X (IARC Scientific Publications No. 164). International Agency for Research on Cancer, Lyon, France, pp1-1365, 2013.

23. Micheli A, Baili P, Quinn M, Mugno E, Capocaccia R and Grosclaude P; EUROCARE Working Group: Life expectancy and cancer survival in the EUROCARE-3 cancer registry areas. Ann Oncol 14 (Suppl 5): v28-v40, 2003.
24. Chen JG (eds): Cancer in Qidong, China (1972-2011). Military Medical Scientific Press, Beijing, China, pp1-346, 2013.

25. Verdecchia A, Capocaccia R, Santaquilani M and Hakulinen T (eds): Methods of survival data analysis and presentation issues. In: Berrino F, Capocaccia R, Estève J (edition): Survival of Cancer Patients in Europe: the EUROCARE-2 Study. (IARC Scientific Publications No. 151). International Agency for Research on Cancer, Lyon, France, pp1-572, 1999.

26. Finnish Cancer Registry. http://www.cancer.fi/@Bin/54321472/ index.html. Accessed December 4, 2016.

27. Hakulinen T and Abeywickrama KH: A computer program package for relative survival analysis. Comput Programs Biomed 19: 197-207, 1985.

28. IDS Silva (eds): Cancer Epidemiology: Principles and Methods. International Agency for Research on Cancer, Lyon, France, pp1-442, 1999

29. Baili P, Di Salvo F, Marcos-Gragera R, Siesling S, Mallone S, Santaquilani M, Micheli A, Lillini R and Francisci S; EUROCARE-5 Working Group: Age and case mix-standardised survival for all cancer patients in Europe 1999-2007: Results of EUROCARE-5, a population-based study. Eur J Cancer: Sep, 2015 (Epub ahead of print).

30. Allemani C, Rachet B, Weir HK, Richardson LC, Lepage C, Faivre J, Gatta G, Capocaccia R, Sant M, Baili P, et al: Colorectal cancer survival in the USA and Europe: A CONCORD high-resolution study. BMJ Open 3: e003055, 2013.

31. Agüero F, Murta-Nascimento C, Gallén M, Andreu-García M, Pera M, Hernández C, Burón A and Macià F: Colorectal cancer survival: Results from a hospital-based cancer registry. Rev Esp Enferm Dig 104: 572-577, 2012.

32. Lagergren J and Mattson F: Diverging trends in recent population-based survival rates in oesophageal and gastric cancer. PLoS One 7: e41352, 2012.

33. Machón Sobrado M, Mozo Carollo I, Tobalina Gómez MC, de Castro Laiz V, Martínez Cobo R, Izarzugaza Lizarraga I and Larrañaga Larrañaga N: Cancer Survival between 1995 and 2004 in the Basque Country, Spain. Rev Esp Salud Publica 86: 293-299, 2012 (In English, Spanish).

34. Tanaka H, Tanaka M, Chen W, Park S, Jung KW, Chiang CJ, Lai MS, Mirasol-Lumague MR, Laudico AS, Sinuraya ES, et al: Proposal for a cooperative study on population-based cancer survival in selected registries in East Asia. Asian Pac J Cancer Prev 10: 1191-1198, 2009.

35. Ito $\mathrm{Y}$, Nakayama $\mathrm{T}$, Miyashiro I, Ioka A and Tsukuma $\mathrm{H}$ : Conditional survival for longer-term survivors from 2000-2004 using population-based cancer registry data in Osaka, Japan. BMC Cancer 13: 304, 2013.

36. Jung KW, Won YJ, Kong HJ, Oh CM, Shin A and Lee JS: Survival of Korean adult cancer patients by stage at diagnosis, 2006-2010: National cancer registry study. Cancer Res Treat 45: $162-171,2013$.

37. Lim RB, Loy EY, Lim GH, Zheng H, Chow KY and Lim ST: Gender and ethnic differences in incidence and survival of lymphoid neoplasm subtypes in an Asian population: Secular trends of a population-based cancer registry from 1998 to 2012. Int J Cancer 137: 2674-2687, 2015.

38. Luo J, Xiao L, Wu C, Zheng Y and Zhao N: The incidence and survival rate of population-based pancreatic cancer patients: Shanghai Cancer Registry 2004-2009. PLoS One 8: e76052, 2013 .

39. Luo SL, Hu RY, Gong WW, Wang H, Pan J, Fei FR and Yu M: Survival rate of colorectal cancer patients during 2005-2010 in Zhejiang province, China. Zhonghua Liu Xing Bing Xue Za Zhi 34: 1194-1197, 2013 (In Chinese).

40. Chiang YC, Chen CA, Chiang CJ, Hsu TH, Lin MC, You SL, Cheng WF and Lai MS: Trends in incidence and survival outcome of epithelial ovarian cancer: 30 -year national population-based registry in Taiwan. J Gynecol Oncol 24: 342-351, 2013.

41. Huang CY, Chen CA, Chen YL, Chiang CJ, Hsu TH, Lin MC, Lai MS, Chen CJ, You SL and Cheng WF: Nationwide surveillance in uterine cancer: Survival analysis and the importance of birth cohort: 30 -year population-based registry in Taiwan. PLoS One 7: e51372, 2012

42. Brenner H, Stegmaier C and Ziegler H: Long-term survival of cancer patients in Germany achieved by the beginning of the third millennium. Ann Oncol 16: 981-986, 2005.

43. Sirri E, Castro FA, Kieschke J, Jansen L, Emrich K, Gondos A, Holleczek B, Katalinic A, Urbschat I, Vohmann C and Brenner H: Recent trends in survival of patients with pancreatic cancer in Germany and the United States. Pancreas 45: 908-914, 2016. 
44. Brenner H, Gondos A and Pulte D: Recent trends in long-term survival of patients with chronic myelocytic leukemia: Disclosing the impact of advances in therapy on the population level. Haematologica 93: 1544-1549, 2008.

45. Lee JY, Jung KW, Park S, Kong HJ, Won YJ, Shin HR, Park EC and Lee JS: Long-term survival of cancer patients in Korea, 1993-2007: National Cancer Registry Study. Asian Pacific J Cancer Prev 11: 1459-1464, 2010.

46. Tiwana MS, Wu J, Hay J, Wong F, Cheung W and Olson RA: 25 year survival outcomes for squamous cell carcinomas of the head and neck: Population-based outcomes from a Canadian province. Oral Oncol 50: 651-656, 2014.

47. Kvammen Ø, Myklebust TÅ, Solberg A, Møller B, Klepp OH, Fosså SD and Tandstad T: Long-term relative survival after diagnosis of testicular germ cell tumor. Cancer Epidemiol Biomarkers Prev 25: 773-779, 2016.

48. Daskivich TJ, Fan KH, Koyama T, Albertsen PC, Goodman M, Hamilton AS, Hoffman RM, Stanford JL, Stroup AM, Litwin MS and Penson DF: Effect of age, tumor risk, and comorbidity on competing risks for survival in a U.S. population-based cohort of men with prostate cancer. Ann Intern Med 158: 709-717, 2013

49. Zhao P, Chen WQ and Kong LZ: Cancer Incidence and Mortality in China (2003-2007). Military Medical Science Press, Beijing, China, pp1-v413, 2012.

50. Jemal A, Bray F, Center MM, Ferlay J, Ward E and Forman D: Global cancer statistics. CA Cancer J Clin 61: 69-90, 2011.

51. Siegel R, Ma J, Zou Z and Jemal A: Cancer statistics, 2014. CA Cancer J Clin 64: 9-29, 2014

52. Chen J, Sankaranrayanan R and Li W: Population-based survival analysis of primary liver cancer in a high-incidence area-Qidong, China during 1972-1991. Zhonghua Yu Fang Yi Xue Za Zhi 31: 149-152, 1997 (In Chinese)

53. Chiang JK and Kao YH: The impact of hospice care on survival and cost saving among patients with liver cancer: A national longitudinal population-based study in Taiwan. Support Care Cance 23: 1049-1055, 2015.

54. Redaniel MT, Laudico A, Mirasol-Lumague MR, Gondos A and Brenner H: Cancer survival differences between European countries and an urban population from the Philippines. Eur J Public Health 21: 221-228, 2011.

55. Yuan Y: Population-based gastric cancer screening in Zhuanghe, Liaoning, from 1997 to 2011. Zhonghua Zhong Liu Za Zhi 34: 538-542, 2012 (In Chinese).

56. Hamashima C, Ogoshi K, Okamoto M, Shabana M, Kishimoto T and Fukao A: A community-based, case-control study evaluating mortality reduction from gastric cancer by endoscopic screening in Japan. PLoS One 8: e79088, 2013.

57. Strong VE, Wu AW, Selby LV, Gonen M, Hsu M, Song KY, Park CH, Coit DG, Ji JF and Brennan MF: Differences in gastric cancer survival between the U.S. and China. J Surg Oncol 112: 31-37, 2015

58. Torre LA, Bray F, Siegel RL, Ferlay J, Lortet-Tieulent J and Jemal A: Global cancer statistics, 2012. CA Cancer J Clin 65 87-108, 2015

59. Chen JG and Kensler TW: Changing rates for liver and lung cancer in Qidong, China. Chem Res Toxicol 27: 3-6, 2014.

60. Fan H, Shao ZY, Xiao YY, Xie ZH, Chen W, Xie H, Qin GY and Zhao NQ: Incidence and survival of non-small cell lung cancer in Shanghai: A population-based cohort study. BMJ Open 5 $\mathrm{e} 009419,2015$.

61. Raaschou-Nielsen O, Andersen ZJ, Beelen R, Samoli E, Stafoggia M, Weinmayr G, Hoffmann B, Fischer P, Nieuwenhuijsen MJ, Brunekreef B, et al: Air pollution and lung cancer incidence in 17 European cohorts: Prospective analyses from the European Study of Cohorts for Air Pollution Effects (ESCAPE). Lancet Oncol 14: 813-822, 2013.

62. Thun MJ, Hannan LM, Adams-Campbell LL, Boffetta P, Buring JE, Feskanich D, Flanders WD, Jee SH, Katanoda K, Kolonel LN, et al: Lung cancer occurrence in neversmokers: An analysis of 13 cohorts and 22 cancer registry studies. PLoS Med 5: e185, 2008.
63. Kris MG,Benowitz SI, Adams S, Diller L, Ganz P,Kahlenberg MS, Le QT, Markman M, Masters GA, Newman L, et al: Clinical cancer advances 2010: Annual report on progress against cancer from the American Society of Clinical Oncology. J Clin Oncol 28: 5327-5347, 2010.

64. Ostenfeld EB, Nørgaard M, Thomsen RW, Iversen LH, Jacobsen JB and Søgaard M: Comorbidity and survival of Danish patients with colon and rectal cancer from 2000-2011: A population-based cohort study. Clin Epidemiol 5 (Suppl 1): S65-S74, 2013.

65. Siegel RL, Miller KD and Jemal A: Cancer statistics, 2016. CA Cancer J Clin 66: 7-30, 2016.

66. Zhang Y: Epidemiology of esophageal cancer. World J Gastroenterol 9: 5598-5606, 2013.

67. Chadwick G, Riley S, Hardwick RH, Crosby T, Hoare J, Hanna G, Greenaway K, Varagunam M, Cromwell DA and Groene O: Population-based cohort study of the management and survival of patients with early-stage oesophageal adenocarcinoma in England. Br J Surg 103: 544-552, 2016.

68. Zeng H, Zheng R, Guo Y, Zhang S, Zou X, Wang N, Zhang L, Tang J, Chen J, Wei K, et al: Cancer survival in China, 2003-2005: A population-based study. Int J Cancer 136: 1921-1930, 2015.

69. Holleczek B and Brenner H: Trends of population-based breast cancer survival in Germany and the US: decreasing discrepancies, but persistent survival gap of elderly patients in Germany. BMC Cancer 12: 317, 2012.

70. Kiderlen M, Bastiaannet E, Walsh PM, Keating NL, Schrodi S, Engel J, van de Water W, Ess SM, van Eycken L, Miranda A, et al: Surgical treatment of early stage breast cancer in elderly: An international comparison. Breast Cancer Res Treat 132: 675-682, 2012.

71. Cronin-Fenton DP, Erichsen R, Mortensen FV, Dikinis S, Nørgaard $M$ and Jacobsen J: Pancreatic cancer survival in central and northern Denmark from 1998 through 2009: A population-based cohort study. Clin Epidemiol 3 (Suppl 1): S19-S25, 2011.

72. Maringe C, Li R, Mangtani P, Coleman MP and Rachet B: Cancer survival differences between South Asians and non-South Asians of England in 1986-2004, accounting for age at diagnosis and deprivation. Br J Cancer 113: 173-181, 2015.

73. Abrahão R, Keogh RH, Lichtensztajn DY, Marcos-Gragera R, Medeiros BC, Coleman MP, Ribeiro RC and Keegan TH: Predictors of early death and survival among children, adolescents and young adults with acute myeloid leukaemia in California, 1988-2011: A population-based study. Br J Haematol 173: 292-2302, 2016

74. Hiom SC: Diagnosing cancer earlier: Reviewing the evidence for improving cancer survival. Br J Cancer 112 (Suppl 1): S1-S5, 2015.

75. Hayat MJ, Howlader N, Reichman ME and Edwards BK: Cancer statistics, trends and multiple primary cancer analyses from the Surveillance, Epidemiology, and End Results (SEER) Program. Oncologist 12: 20-37, 2007.

76. Eisemann N, Waldmann A and Katalinic A: Imputation of missing values of tumour stage in population-based cancer registration. BMC Med Res Methodol 11: 129, 2011.

77. Jensen OM, Parkin MD and MacLennan R (eds): Cancer Registration: Principles and Methods (IARC Scientific Publications No. 95). International Agency for Research on Cancer, Lyon, France, pp1-288, 1991. 